\title{
Additional arterial conduits in coronary artery bypass surgery: Finally coming of age
}

\author{
Mario Gaudino, MD, ${ }^{\mathrm{a}}$ Michael J. Mack, MD, ${ }^{\mathrm{b}}$ and David P. Taggart, $\mathrm{MD}^{\mathrm{c}}$
}

\footnotetext{
From the ${ }^{\mathrm{a} D e p a r t m e n t}$ of Cardiothoracic Surgery, Weill Cornell Medicine, New York, NY; ${ }^{\mathrm{b}}$ Department of Cardiac Surgery, The Heart Hospital Baylor Plano, Plano, Tex; and ${ }^{\mathrm{c} D e p a r t m e n t}$ of Cardiovascular Surgery, University of Oxford, Oxford, United Kingdom.

Disclosures: Authors have nothing to disclose with regard to commercial support.

This will copublish in the Journal of the American College of Cardiology.

Received for publication April 30, 2018; accepted for publication May 13, 2018; available ahead of print June 18, 2018.

Address for reprints: Mario Gaudino, MD, Department of Cardiothoracic Surgery, Weill Cornell Medicine, $525 \mathrm{E}$ 68th St, New York, NY 10065 (E-mail: mfg9004@med.cornell.edu).

J Thorac Cardiovasc Surg 2018;156:541-3

$0022-5223 / \$ 36.00$

(C) 2018 by American College of Cardiology Foundation. Published by Elsevier. https://doi.org/10.1016/j.jtcvs.2018.05.002
}

In April 1968, Rene Favaloro published his first description of the coronary artery bypass graft $(\mathrm{CABG})$ surgery. ${ }^{1}$ In the 50 years since then, CABG has been arguably the most intensively studied surgical procedure. One of the most important and persistent controversies has been the ideal choice of conduits for revascularization, and in particular, whether the use of multiple arterial grafts leads to significantly improved long-term outcomes.

Over the past 5 decades, a substantial amount of observational data reporting the beneficial effects of multiple arterial grafts has been published. The overwhelming majority of series reported a survival advantage, using predominantly either internal thoracic or radial arteries. ${ }^{3,4}$ Notably, even with propensity matching, these studies were almost exclusively based on retrospective observational data, and until $<2$ years ago, no adequately powered, comparative, randomized trial had been published.

The better outcomes associated with arterial grafts are hypothesized to result from their superior angiographic patency. Randomized trials and a network meta-analysis have consistently shown arterial conduits to have better mid- and long-term patency rates than saphenous vein grafts, providing a likely mechanistic explanation of the improved outcomes associated with the use of arteries. ${ }^{5}$ Of note, this finding is currently based on a larger number of trials and patients for the radial artery ( 9 trials, $n=2366$ ) than for the right internal thoracic artery (2 trials, $\mathrm{n}=304$ ) (Figure 1 ).

Such observational evidence has been progressively incorporated into guidelines and professional societies' position papers, so that the use of multiple arterial grafts for CABG is increasingly recommended in U.S. and European guidelines and in a recent Society of Thoracic Surgeons position paper. $^{6-8}$

\section{ARTERIAL REVASCULARIZATION TRIAL}

In this scenario of nonrandomized (but widely accepted) evidence of the superiority of arterial grafts, the American Heart Association's November 2016 presentation and

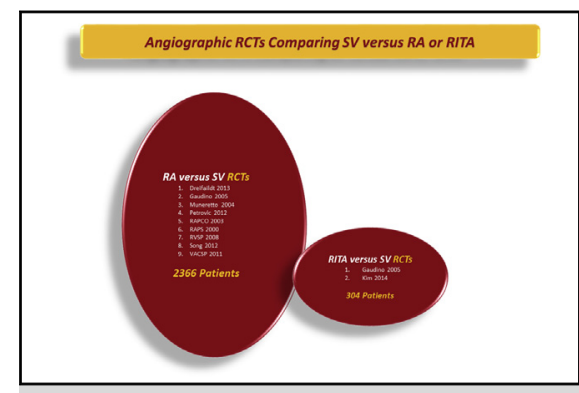

Saphenous vein $(S V)$ vs radial artery $(R A)$ or right internal thoracic artery (RITA) in RCTs.

Central Message

It is time to clarify the effect of the procedural characteristics of the coronary bypass operation on clinical outcomes. Randomized trials and international collaboration will be key for this.

publication of the planned 5-year interim analysis (of 10year survival, a primary outcome) of ART (Arterial Revascularization Trial) surprised the CABG world. ${ }^{9}$ ART is, by far, the largest randomized study on the use of arterial grafts, involving 28 centers in 7 countries and 3,102 patients randomized to receive single internal thoracic arteries (SITAs) or bilateral internal thoracic arteries (BITAs). At 5 years, no difference between the 2 arms in survival and event-free survival was found (hazard ratio: 1.04 ; $95 \%$ confidence interval: 0.81 to 1.32 ; and hazard ratio: $0.96 ; 95 \%$ confidence interval: 0.79 to 1.17 , respectively) and the survival curves were very similar. It remains to be seen if any significant differences emerge at the final 10-year followup. Notably, at 5 years, a treatment age interaction close to statistical significance was observed in favor of BITAs in patients under 70 years of age.

There are, however, several potential limitations to ART. First, the lower than predicted event rates resulted in an underpowered sample size at 5 years. Second, overall, there was a high differential crossover rate, with $15 \%$ of BITAs crossing to SITAs, but only $4 \%$ of SITAs crossing to BITAs. Per surgeon, the BITA to SITA crossover rate varied from $0 \%$ to $100 \%$, raising questions regarding some surgeons' experience with BITA grafting. ${ }^{10}$ Third, around $20 \%$ of patients receiving a SITA graft also received a radial artery graft, which may have further narrowed any potential differences between SITA and BITA. ${ }^{4}$ Fourth, particularly high compliance with guideline-directed medical therapy may have reduced the overall risk of vein graft failure. 


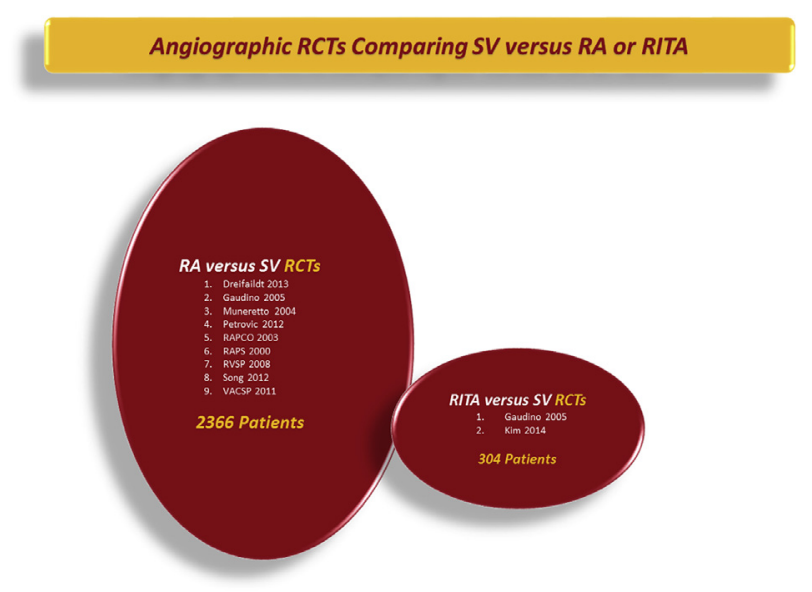

FIGURE 1. Saphenous vein versus radial artery or right internal thoracic artery in randomized controlled trials. There have been 9 randomized trials ( $\mathrm{n}=2366)$ comparing the patency rate of the radial artery $(R A)$ and the saphenous vein $(S V)$. For the right internal thoracic artery (RITA), the comparison has been performed in 2 randomized studies $(\mathrm{n}=304) . R C T$, Randomized controlled trial.

Despite these limitations, ART remains the most solid available evidence comparing SITA versus BITA grafts. Furthermore, although the results of ART contradict much of the results of published observational studies, they are consistent with Cleveland Clinic results from almost 20 years ago reporting a survival benefit of BITA grafts only after 5 years. ${ }^{11}$

Nevertheless, the results of the 5-year interim analyses of ART were a wake-up call for the CABG community, leading to critical re-evaluations of existing published evidence, recognizing the limitations of even the highest-quality observational evidence. ${ }^{12}$

Even before the final 10-year results are known, ART has already taught us a seminal lesson: randomized data are mandatory to appropriately address the question of the benefit of the use of multiple arterial grafts for CABG. Observational studies have intrinsic limitations that are impossible to neutralize, even using the most complex statistical techniques for risk adjustment. ${ }^{12}$

\section{THE RADIAL PROJECT}

RADIAL (Radial Artery Database International ALliance) is an international alliance of investigators who aim to provide the basis for meta-analytic studies on the use of the radial artery for CABG. The project was initiated in March 2015, and is funded by the Department of Cardiothoracic Surgery of Cornell Medicine in New York. The first RADIAL meeting was held in April 2016 at the 96th annual meeting of the American Association for Thoracic Surgery in Baltimore, Maryland.

RADIAL's primary objective was to combine individual patient data from all of the randomized trials comparing the radial artery and the saphenous vein as supplemental conduits for CABG. Using a sample size calculation based on published contemporary CABG trials, the RADIAL investigators estimated that the analysis would have enough power to detect moderate differences in cardiac events at the midterm follow-up. ${ }^{13}$

Until RADIAL, all of the individual randomized trials comparing the radial artery and the saphenous vein had primary angiographic outcomes and were largely underpowered to evaluate differences in clinical events. Although the superior patency rate of the radial artery was established, there was no evidence available on any potential clinical benefit for outcomes.

The principal investigators of all 6 randomized trials on the radial artery with extended follow-up (from Australia, Canada, Korea, Italy, Serbia, and the United Kingdom) agreed to provide individual patient data and then followup data. The results were presented at the 98th annual meeting of the American Association for Thoracic Surgery and published simultaneously in the New England Journal of Medicine in April 2018, 50 years after the Favaloro paper was published.

At a mean follow-up of 5 years, use of the radial artery was associated with a significantly lower risk of adverse cardiac events, repeat revascularization, and myocardial infarction, and a better patency rate compared with the saphenous vein (patency rates $91.9 \%$ vs $80.2 \%$; $P=.001) .{ }^{14}$ At 5 years, there were no significant differences in mortality $(7.5 \%$ for radial artery and $8.4 \%$ for saphenous vein; $P=.68$ ), but with the almost exponential increase in the risk of occlusion of vein grafts in the midand long-term, it is not yet known if a difference in survival will become apparent at longer follow-up. This was the first time in the history of CABG that clinical benefits associated with the use of an additional arterial graft were demonstrated by randomized trials.

\section{IMPORTANCE OF INTERNATIONAL COLLABORATION}

The 5-year analysis of ART and the consequent critical revision of observational published studies on the use of additional arterial grafts clearly indicate that randomization is the only way to neutralize the unmeasurable confounders intrinsic to observational studies comparing single versus multiple arterial grafts. ${ }^{12}$ However, randomized trials are expensive and extremely difficult to realize. ART will publish its final 10-year results this year, a landmark achievement for published CABG studies. A second large randomized trial comparing single versus multiple arterial grafts (ROMA [Randomized comparison of the clinical Outcome of single versus Multiple Arterial grafts]) is currently in its initial phase of enrollment, and analysis of the primary outcome will not be completed for another 5 to 7 years. 
In the meantime, RADIAL has shown the potential of international collaboration and data sharing. One of the arguably most important results in the history of CABG has been achieved with very limited costs and without any external funding, thanks to the support and dedication of investigators on 4 continents. This kind of collaboration exemplifies the possibility of producing high-quality scientific data in a reasonable amount of time and with acceptable costs. RADIAL is now working on secondary outcomes, including specific angiographic analyses and comparison with large, observational registries.

\section{SUMMARY}

At 50 years, CABG has entered a mature phase. It is now time to clarify the effect of procedural characteristics on clinical outcomes and to define the most appropriate strategy for each individual patient. Observational data have intrinsic biases and should only be considered hypothesisgenerating. Randomized trials remain the only way to solve the conundrum of arterial grafts. International collaboration will be key to the success of this process.

\section{References}

1. Favaloro RG. Saphenous vein autograft replacement of severe segmental coronary artery occlusion. Ann Thorac Surg. 1968;5:334-9.

2. Barner HB. Double internal mammary-coronary artery bypass. Arch Surg. 1974; 109:627-30.

3. Buttar SN, Yan TD, Taggart DP, Tian DH. Long-term and short-term outcomes of using bilateral internal mammary artery grafting versus left internal mammary artery grafting: a meta-analysis. Heart. 2017;103:1419-26.

4. Gaudino M, Ruel M, Taggart DP, for the ATLANTIC (ArTeriaL grAftiNg inTernatIonal Consortium) Alliance. Blaise Pascal and the evidence on the use of mul- tiple arterial grafts for coronary artery bypass surgery after the interim analysis of the arterial revascularization trial. Curr Opin Cardiol. 2018;33:245-8.

5. Benedetto U, Raja SG, Albanese A, Amrani M, Biondi-Zoccai G, Frati G. Searching for the second best graft for coronary artery bypass surgery: a network meta-analysis of randomized controlled trials. Eur J Cardiothorac Surg. 2015; 47:59-65; discussion 65.

6. Hillis LD, Smith PK, Anderson JL, Bittl JA, Bridges CR, Byrne JG, et al. 2011 ACCF/AHA guideline for coronary artery bypass graft surgery: a report of the American College of Cardiology Foundation/American Heart Association task force on practice guidelines. J Am Coll Cardiol. 2011;58:e123-210.

7. Windecker S, Kolh P, Alfonso F, Collet JP, Cremer J, Falk V, et al; Authors/Task Force members. 2014 ESC/EACTS guidelines on myocardial revascularization: the task force on myocardial revascularization of the European Society of Cardiology (ESC) and the European Association for Cardio-Thoracic Surgery (EACTS) developed with the special contribution of the European Association of Percutaneous Cardiovascular Interventions (EAPCI). Eur Heart J. 2014;35: 2541-619.

8. Aldea GS, Bakaeen FG, Pal J, Fremes S, Head SJ, Sabik J, et al. The Society of Thoracic Surgeons clinical practice guidelines on arterial conduits for coronary artery bypass grafting. Ann Thorac Surg. 2016;101:801-9.

9. Taggart DP, Altman DG, Gray AM, Lees B, Gerry S, Benedetto U, et al; for the ART Investigators. Randomized trial of bilateral versus single internal-thoracicartery grafts. N Engl J Med. 2016;375:2540-9.

10. Benedetto U, Altman DG, Flather M, Gerry S, Gray A, Lees B, et al; for the Arterial Revascularization Trial Investigators. Incidence and clinical implications of intraoperative bilateral internal thoracic artery graft conversion: insights from the arterial revascularization trial. J Thorac Cardiovasc Surg. 2018;155:2346-55.e6.

11. Lytle BW, Blackstone EH, Loop FD, Houghtaling PL, Arnold JH, Akhrass R, et al. Two internal thoracic artery grafts are better than one. J Thorac Cardiovasc Surg. 1999;117:855-72.

12. Gaudino M, Di Franco A, Rahouma M, Tam DY, Iannaccone M, Deb S, et al. Unmeasured confounders in observational studies comparing bilateral versus single internal thoracic artery for coronary artery bypass grafting: a meta-analysis. J Am Heart Assoc. 2018;7:e08010.

13. Gaudino M, Leonard J, Taggart DP. Lessons learned from Radial Artery Database Alliance (RADIAL). Ann Cardiothorac Surg. March 14, 2018 [E-pub ahead of print].

14. Gaudino M, Benedetto U, Fremes S, Biondi-Zoccai G, Sedrakyan A, Puskas JD, et al; for the RADIAL Investigators. Radial artery versus saphenous vein in coronary artery bypass surgery. $N$ Engl J Med. 2018;378:2069-77. 